\title{
APRENDIZAGENS E SABERES DA DOCÊNCIA UNIVERSITÁRIA EM UMA LICENCIATURA EM MATEMÁTICA ${ }^{1}$
}

\section{LEARNING AND EXPERTISE OF THE UNIVERSITY TEACHING IN A UNIVERSITY DEGREE ON MATHEMATICS}

Fabricia Nates dos Santos Galvão ${ }^{2}$

ORCID iD: 0000-0002-0508-2725

Loriége Pessoa Bitencourt ${ }^{3}$

ORCID iD: 0000-0002-7643-2091

\begin{abstract}
RESUMO
Neste artigo apresentamos um recorte da pesquisa de mestrado, desenvolvida junto ao Programa de PósGraduação em Educação - PPGEdu, Curso de Mestrado em Educação, da Universidade do Estado de Mato Grosso (UNEMAT), que tem por objetivo analisar como um docente de uma Licenciatura em Matemática aprende a docência universitária e quais saberes mobiliza para atuar na Educação Superior. É uma investigação qualitativa, do tipo estudo de caso, cuja coleta de dados contou com questionário de caracterização e entrevista semiestruturada. Dentre os autores que subsidiaram a pesquisa destacam-se Zabalza (2004), Mizukami et al. (2002), Bitencourt (2014; 2017), Tardif (2014). Conclui-se, de modo geral, que o docente possui, de forma singular, elementos que influenciam as suas aprendizagens docentes, configuradas pelos seus percursos de formação pessoal ou profissional, realimentadas pelos diferentes saberes construídos na significação das suas experiências. O docente de Matemática aqui pesquisado aprende a docência na prática cotidiana em sala de aula, mobilizando os saberes necessários à sua atuação fundamentados nos saberes da experiência.
\end{abstract}

Palavras-chave: Pedagogia Universitária. Docente de Licenciatura em Matemática. Educação Superior.

\section{ABSTRACT}

This article introduces an approach of the Master Degree research carried out within the Graduation Program in Education - PPGEdu - Master Degree in Education of the University of Mato Grosso (UNEMAT), that has the objective of analyzing how a teacher of the University Degree in Mathematics

\footnotetext{
${ }^{1}$ Um artigo muito semelhante, que originou boa parte das reflexões feitas neste, foi aprovado e apresentado como comunicação oral, no Encontro Nacional de Educação Matemática - XIII ENEM, cuja temática foi Educação Matemática com as Escolas da Educação Básica: interfaces entre pesquisas e salas de aula, realizado pela Universidade do Estado de Mato Grosso/UNEMAT, com apoio da Sociedade Brasileira de Educação Matemática - SBEM, entre os dias 14 a 17 de julho/2019, em Cuiabá/MT.

${ }^{2}$ Mestra em Educação pela Universidade do Estado de Mato Grosso (UNEMAT). Professora Contratada pela Universidade do Estado de Mato Grosso (UNEMAT), Cáceres, MT, Brasil. Endereço para correspondência: Rua das Hortências, 617, Jardim Padre Paulo, Cáceres, MT, Brasil, CEP: 78217-630. E-mail: fabricia_nates@hotmail.com.

${ }^{3}$ Doutora em Educação pela Universidade Federal do Rio Grande do Sul (UFRGS). Professora Efetiva na Universidade do Estado de Mato Grosso (UNEMAT). Docente do Quadro Permanente do Programa de PósGraduação em Educação (PPGEdu/UNEMAT), na linha de pesquisa: Formação de Professores, Políticas e Práticas Pedagógicas, Cáceres, MT, Brasil. Endereço para correspondência: Rua Etiópia, 05, Vila Mariana, Cáceres, MT, Brasil, CEP: 78210-384. E-mail: lori.pessoa@ hotmail.com.
} 
learns the university teaching and which knowledge he mobilizes to perform in High Education. It is a qualitative research of the case study type while the data were collected through the application of a characterization questionnaire and semi-structured interview. Among the authors that supported the research, stand out Zabalza (2004), Mizukami et al (2002), Bitencourt (2014; 2017), Tardif (2014). The general conclusion is that the teacher has in a unique way the elements that influence his teaching learning, configured by his trajectories of personal or professional education with the feedback of different expertise inputs constructed within the meaning of his experiences. The Mathematics teacher researched herein learns how to teach in the daily practice in the classroom by mobilizing the knowledge needed to his performance grounded in the knowledge from the experience.

Key words: University Pedagogy. Teacher of the University Degree in Mathematics. High Education.

\section{INTRODUÇÃO}

Com a expansão da Educação Superior surgem novos desafios no interior das universidades, as quais são lugares específicos e especializados de formação que não podem ser consideradas apenas um espaço de capacitação para o mercado de trabalho, mas um ambiente que vise à formação de indivíduos críticos, pensantes e capazes de promover inovações na sociedade (ZABALZA, 2004).

Nesse mesmo sentido, Galvão e Bitencourt (2017) destacam que o aumento do número de instituições de Educação Superior e, consequentemente, de docentes universitários impulsionam a crescente procura por qualificação profissional nos Programas de PósGraduação Stricto Sensu, em nível de mestrado e doutorado.

Com isso, cresce, gradativamente, o número de pesquisas centradas no cotidiano da educação, tanto da Básica quanto da Superior. E para a presente investigação nos interessam as pesquisas sobre a Educação Superior, pois elas podem ser um aspecto importante para melhorar a qualidade da formação desenvolvida na Universidade.

Por essa razão, na pesquisa realizada durante o mestrado defendemos a formação dos docentes universitários como um continuum - parte importante do processo de seu desenvolvimento profissional - no qual aprendem a docência de forma singular e constante, mobilizando saberes para o exercício da sua profissão, a docência universitária (GALVÃO, 2019).

A nossa pesquisa de Mestrado em Educação foi realizada com docentes universitários lotados nas Faculdades de um dos 13 campus universitários da Universidade do Estado de Mato Grosso (UNEMAT). No campus universitário, lócus da pesquisa concluída, existem seis Faculdades com seus diferentes cursos de graduação, tanto de bacharelados quanto de licenciaturas. Assim, em um universo de 13 cursos de graduação do referido campus 
selecionamos os que seriam pesquisados, utilizando como critério o curso com maior número de docentes doutores efetivos que neles lecionavam, e selecionamos, assim, três licenciaturas e três bacharelados.

Entre os cursos de graduação selecionados estava a Licenciatura Plena em Matemática e nela um docente universitário com mais de vinte anos de experiência na Educação Superior. Desse modo, trazemos para este artigo somente as reflexões feitas com o docente universitário da Licenciatura em Matemática, pois nos interessa discutir as aprendizagens e os saberes desse docente universitário.

O objetivo da pesquisa de mestrado foi analisar como os docentes aprendem a docência universitária e que saberes mobilizam para atuar na Educação Superior, tendo como foco principal de investigação a busca por resposta à seguinte questão problema: Como os docentes dos cursos de licenciaturas e bacharelados da Universidade do Estado de Mato Grosso, do Campus Universitário "Jane Vanini” de Cáceres-MT, aprendem a docência universitária, e que saberes mobilizam para atuar na Educação Superior? (GALVÃO, 2019).

Para tanto, estruturamos o presente artigo da seguinte forma: primeiramente, apresentamos um breve referencial teórico que fundamenta a nossa pesquisa, dando destaque à Pedagogia Universitária, às aprendizagens e aos saberes da docência universitária. Em seguida, abordamos os aspectos metodológicos adotados para o desenvolvimento da investigação que resultou na produção deste estudo. Expomos, em seguida, as análises dos dados coletados, e, por fim, tecemos algumas considerações acerca deste artigo.

\section{REFERÊNCIAL TEÓRICO}

Diante da complexidade da docência universitária, estudos apontam que o desenvolvimento profissional do docente universitário merece o mesmo destaque que os estudos sobre formação, pois o desenvolvimento profissional envolve uma dimensão maior, englobando, inclusive, as discussões sobre formação, tanto nos programas de formação inicial quanto continuada, as quais visam valorizar a formação não mais baseada na racionalidade técnica (PIMENTA; ANASTASIOU, 2014). Isto é, para atuar na docência não bastam apenas os conhecimentos específicos na área de atuação do docente universitário, mas também a sua experiência profissional para atender à grande demanda da Educação Superior na contemporaneidade, pois, à medida que são compartilhados estudos, vivências e práticas, as aprendizagens vão se solidificando e, consequentemente, favorecendo o desenvolvimento. 
Durante levantamento bibliográfico inicial para a realização desta pesquisa observamos que os estudos sobre a formação de professores, aprendizagens e saberes docentes se direcionavam a Educação Básica, havendo um menor número de investigações centradas na docência da Educação Superior e voltadas, por exemplo, aos temas desta pesquisa.

Assim, optamos por realizar nossa pesquisa na área da Pedagogia Universitária, que é campo potencializador de estudos sobre a docência universitária e interlocutor da formação do docente universitário, das suas aprendizagens na docência e da sua atuação. Conforme Soares e Cunha (2010), a Pedagogia Universitária é considerada um campo fértil de pesquisas por se interessar pelo processo de ensino e aprendizagem, pelos saberes da docência e pela teoria e a prática da formação de professores.

Por essa razão, refletir sobre a Pedagogia Universitária nos cursos de licenciaturas é pensar sobre a possibilidade de os docentes (re)construírem suas aprendizagens e mobilizarem todos os saberes necessários ao exercício da profissão docente, pois, conforme Bolsan e Isaia (2010), a Pedagogia Universitária é um campo que visa à aprendizagem da docência, envolvendo a apropriação de conhecimentos, saberes e fazeres na atividade de ser docente em seus diversos campos de atuação. E essas autoras salientam:

[...] a pedagogia universitária pode ser compreendida como um espaço em movimento, no qual podemos analisar e compreender os fenômenos de aprender e de ensinar as profissões, sobretudo, um espaço no qual a própria docência universitária em ação pode ser revisitada e constantemente reconstruída. (BOLSAN; ISAIA, 2010, p. 23, grifo dos autores)

Assim, percebe-se que a Pedagogia Universitária envolve todos os aspectos da docência universitária, inclusive favorecendo a compreensão das suas aprendizagens, do modo como o docente aprende e ensina na universidade. Além disso, é um espaço em que a docência universitária pode ser constantemente (re)construída, buscando melhorias para as atividades que lhe são inerentes - o ensino, a pesquisa e a extensão.

Nesse sentido, discutir as aprendizagens do docente universitário requer que compreendamos esse processo diante dos movimentos construtivos que reúnem um conjunto de etapas produzidas e adquiridas pelo docente à medida que ele atua na docência universitária, considerando que, nesse processo, a mobilização e a apropriação de saberes docentes são fundamentais ao seu exercício na docência.

Nessa perspectiva, "a aprendizagem da docência deve ser concebida como um processo continuum de formação que não tem tempo nem espaço, fazendo-se e refazendo-se constantemente" (BITENCOURT; DARSIE, 2015, p. 124), ou seja, para as autoras, o docente 
universitário aprende a todo o momento, tanto em espaços formais quanto informais. Dessa forma, ao refletirmos sobre as aprendizagens da docência universitária percebemos a necessidade de uma atenção redobrada sobre as experiências e saberes que vão sendo construídos pelos docentes cotidianamente nos diferentes espaços e cenários de formação. (SANTOS; POWACZUK, 2012).

As aprendizagens da docência, portanto, são consideradas um processo, mediante o qual o docente universitário, no seu cotidiano e nos variados espaços de formação — sala de aula, cursos, eventos, congressos, pesquisas e extensões, dentre outros — vai constituindo-se docente, aprendendo a lidar com as diversas situações prazerosas, ou não, do ambiente universitário. Assim, aprender a docência requer mais do que o ensino de conteúdos específicos a serem trabalhados, isto porque o docente tem outras atividades para desenvolver, as quais demandam responsabilidade e comprometimento com os encaminhamentos da atividade e do exercício da docência universitária.

Sob essa ótica, Bitencourt e Darsie (2015, p. 124), ao pesquisarem a respeito da docência do professor formador de professores de Matemática para a Educação Básica, definem que

\footnotetext{
a aprendizagem da docência é uma formação plural, constituída pelo amálgama de saberes oriundos de vários contextos, circunstâncias e instituições, assim como da experiência pessoal e profissional, dos saberes das disciplinas e atividades práticas proporcionadas pelos cursos de formação. (BITENCOURT; DARSIE, 2015, p. 124).
}

Para essas autoras, a aprendizagem da docência vai além de adicionar ou substituir conhecimentos, pois ela é constituída de vários saberes oriundos de vários espaços e das experiências do próprio docente, o que significa considerar que os docentes que atuam nos cursos de licenciatura são sujeitos cuja atividade profissional lhes proporciona diversas aprendizagens.

Mizukami et al. (2002, p. 16) atribuem grande força às experiências vividas pelo docente ao longo da carreira e a todo o processo continuum, e consideram a necessidade de estabelecer um fio condutor nesse processo, no qual, aos poucos, o docente vai produzindo os sentidos e significados ao longo da sua trajetória, que são condicionantes para manter os nexos entre a formação inicial, a continuada e as experiências vividas. Assim, para esses autores, a reflexão promove todos esses nexos, que vão sendo significados, ocorrendo, dessa forma, as aprendizagens da docência.

Nesse processo de reflexão, a partir das experiências, o docente (re) constrói um conjunto de saberes para a sua atuação profissional, e, significativamente, aprende a ser 
docente, pois, segundo Silva e Monteiro (2007, p. 59), “o exercício do magistério é uma profissão aprendida: não se nasce professor, aprende-se a ser professor no dia a dia". O que significa que todo docente vai, aos poucos, tornando-se e aprendendo a ser o docente que é e como ensinar. Nesse sentido, Mizukami et al. (2002, p. 48) salientam que

\begin{abstract}
aprender a ensinar é um processo complexo que envolve fatores afetivos, cognitivos, éticos, de desempenho, entre outros [...] não se dispõe, até o momento, de um referencial teórico coerente e abrangente, de uma teoria geral de conhecimento sobre aprendizagem profissional que possa iluminar processos de desenvolvimento profissional de professores de modo a informar o desenho de cursos de formação básica e programas de formação continuada. (MIZUKAMI, et al., 2002, p. 48).
\end{abstract}

As reflexões em torno do ato de ensinar nos conduzem ao entendimento de que as aprendizagens da docência ocorrem de forma singular para cada docente. E isso depende de inúmeros fatores, dentre os quais destacamos a formação, a qual não deve ser analisada de forma simplista, pois há diversas maneiras de concebê-la, não havendo, até o momento, um referencial teórico sobre a aprendizagem, isto é, quando e de que modo o docente deve aprender a ensinar na docência. Assim, conforme Mizukami et al. (2002), a aprendizagem para ensinar se intensifica e implica o envolvimento do próprio docente, configurando o seu percurso pessoal e profissional que se faz na (re)construção dos seus saberes docentes. Assim, as suas aprendizagens são um processo desenvolvimental que requer tempo para que, de fato, ocorra a aprendizagem.

Ressaltamos que em todo processo de aprender a docência, o docente precisa significar seus saberes e experiências adquiridas para além do conteúdo e do pedagógico, e, conforme Tardif (2014), dos saberes experienciais, saberes que os docentes, no exercício das suas funções e práticas, desenvolvem, baseados em seu trabalho cotidiano e no conhecimento de seu meio, os quais nascem da experiência e são por ela validados, incorporando-se à experiência individual e também coletiva sob a forma de habitus e de habilidades de saber-fazer e de saberser. Por essa razão, neste estudo, evidenciaremos os saberes da experiência ligados aos saberes próprios do docente universitário.

Entendemos, a partir de Tardif (2014), que o saber docente é um saber plural, relacionado à pessoa e à identidade do docente, e também à sua experiência de vida pessoal e profissional. Por isso, em sua prática, ele utiliza diferentes saberes que são fundamentais para o trabalho na docência, pois a dimensão da profissão docente lhe atribui um status de prática que se articula com vários saberes, provenientes de diversas fontes. 
Nessa direção, os saberes docentes são produzidos no cotidiano da prática docente, na trajetória profissional, e resultam das reflexões críticas feitas pelos sujeitos sobre a sua prática. Dessa forma, os saberes da experiência são promovedores das aprendizagens da docência universitária, pois são saberes ligados, diretamente, a uma íntima relação com o trabalho do docente, seja na escola ou na universidade, gerando vivências que, (re)significadas pelos docentes, transformam-se em experiências. Assim, a experiência é considerada uma reflexão sobre as práticas vividas e a partir delas há a (re)significação por parte dos sujeitos que as viveram (BITENCOURT; DARSIE, 2015). Ou seja, só se torna uma experiência quando as ações são refletidas por parte dos sujeitos, e essa reflexão sobre as ações desencadeiam um processo de ressignificação.

E Bitencourt (2017), por sua vez, ressalta que esse elo de reflexão também está relacionado à ideia de formação do docente como um processo continuum, que percorre toda a carreira profissional dele, integrando as aprendizagens da docência e possibilitando a transformação destas, produzindo, inclusive, saberes e experiências.

Nesse sentido, a partir de Tardif (2014) e Mizukami et al. (2002), entendemos que a aprendizagem nesse contexto da docência universitária é um processo em que o docente adquire e se apropria de conhecimentos, significando-os e transformando-os em saberes e fazeres, habilidades, atitudes, possibilitando aprender a partir de uma realidade concreta da sua atividade docente.

Consideramos importante reconhecer que as aprendizagens da docência não se esgotam no aprender o que ensinar, como ensinar, e com que didáticas, pois a docência ainda é um lento e tenso processo de aprendizado coletivo, do qual não saem produtos prontos dos currículos de formação. Sendo assim, é o que nos motiva a aprofundar o como se aprende, quando se aprende a ser docente, suas fontes de aprendizagens que podem estar interligadas aos sujeitos da ação e nas condições reais do trabalho docente.

\section{METODOLOGIA DA PESQUISA}

Como já exposto, o lócus da pesquisa de mestrado foi a Universidade do Estado de Mato Grosso (UNEMAT), Campus Universitário “Jane Vanini”, em Cáceres-MT, e os cursos de graduação de Licenciaturas em Matemática, Pedagogia e Geografia; e os cursos de graduação de Bacharelados em Agronomia, Enfermagem e Direito. Assim, foram selecionados os participantes desta pesquisa, compondo um universo de oito docentes universitários, a partir do 
Lotacionograma do Quadro Docente de cada curso de graduação do semestre letivo de 2018/1, cujo cargo era efetivo, estando em pleno exercício, com qualificação de doutorado e maior tempo na carreira docente e/ou, no máximo, cinco anos de atuação na mesma instituição e mesmo campus (GALVÃO, 2019).

Ressaltamos que, do universo de cursos de graduação e participantes da pesquisa, anteriormente mencionados, para este artigo foi feito um recorte, evidenciando somente o curso de graduação em Licenciatura em Matemática, do qual foi selecionado apenas um docente universitário com anos de atuação na UNEMAT, denominado Docente Matemática (DMAT) nesta pesquisa.

Com o intuito de encontrar a resposta para a questão-problema e alcançar o objetivo proposto para a pesquisa, optamos por uma investigação de caráter qualitativo, por nos permitir uma compreensão mais esclarecedora do objeto de estudo. Além disso, nos oferece a possibilidade de estabelecer relação com o objeto a ser estudado, de maneira que os dados possam ser obtidos a partir do contato direto com a fonte de pesquisa (BOGDAN; BIKLEN, 1994).

A pesquisa realizada caracterizou-se como um Estudo de Caso, pois, segundo Yin (2015), esse tipo de estudo investiga um fenômeno contemporâneo a partir do contexto em que está inserido e tendo bem delimitado o caso a ser estudado. Ressaltamos que se trata de um estudo de caso, pois permite que a pesquisadora foque em um caso específico, em uma perspectiva holística da realidade de vida e de mundo. Logo, definimos como caso: o Docente do curso de Licenciatura em Matemática. E frisamos que as aprendizagens e saberes da docência universitária são as variáveis, a partir das quais discutimos e refletimos sobre o caso mencionado.

Destacamos que os instrumentos utilizados para a coleta de dados foram: um questionário de caracterização, construído por meio da ferramenta on-line Google Forms e encaminhado por e-mail ao participante da pesquisa, e a entrevista semiestruturada.

Para a análise dos dados aprofundamos nossos estudos sobre as técnicas analíticas de Yin (2015). Segundo esse autor, nenhuma técnica deve ser considerada fácil, pois todas precisam de muita prática para ser utilizadas com eficácia, e, além disso, o principal objetivo de um pesquisador deve ser trabalhar minuciosa e introspectivamente para construir seu próprio repertório analítico.

Assim, para este estudo utilizamos a técnica analítica de combinação padrão "baseada nas descobertas do seu estudo de caso - com um padrão previsto antes da sua coleta de dados 
(ou com várias previsões alternativas)" (YIN, 2015, p. 147). Para o autor, essa técnica referese à comparação do padrão baseado no empirismo com o padrão previsto, e quando estes são semelhantes os resultados obtidos podem fortalecer a validade interna do caso estudado.

É importante ressaltar que para a análise dos dados foi realizado, inicialmente, um processo de categorização dos dados coletados, do qual emergiu a categoria experiência, a partir de duas variáveis de pesquisa — aprendizagens e saberes —, de modo a relacioná-las com o acervo teórico construído no decorrer da investigação e da resposta que obtivemos do participante.

\section{ANÁLISES E RESULTADOS}

Ressaltamos que neste artigo optamos por evidenciar somente os aspectos relacionados às aprendizagens e aos saberes do docente universitário do Curso de Licenciatura em Matemática, denominado, na pesquisa, pelo codinome Docente Matemática (DMAT), a fim de ilustrarmos o relato desse docente sobre como aprende a docência universitária e que saberes ele mobiliza para atuar na Educação Superior.

É importante, nesse processo de análise, apresentarmos o perfil do docente universitário investigado: o DMAT é do gênero masculino, tem 57 anos, é formado pelo Instituto de Educação Superior de Cáceres (IESC) - atual UNEMAT, no curso de Licenciatura Curta em Ciências e Matemática, e, posteriormente, realizou uma complementação na Universidade Federal de Mato Grosso (UFMT), no curso de Bacharelado em Habilitação Parcelada em Física. Esse docente possui doutorado, sendo um dos nossos critérios para a seleção dos participantes, e já atuou na UNEMAT, primeiro na situação de interino, desde 1991, sendo efetivado por concurso público em 1994. Desse modo, ressaltamos que o DMAT foi considerado, nesta investigação, um docente experiente, com anos de atuação na carreira docente, pois exerce a docência universitária há 27 anos.

Em relação à profissão docente, ao questionarmos sobre qual era a sua profissão, o DMAT afirmou de imediato que se considerava professor, demonstrando possuir uma identidade profissional firmada com a profissão de docente, a qual ele escolheu para seguir carreira. Assim, Pimenta (2012) ressalta que a identidade é própria de cada sujeito, pois a profissão de professor, semelhante às demais, é construída a partir de contextos e momentos historicamente situados pelo sujeito envolvido. 
Dessa forma, o DMAT, quando indagado sobre a experiência em outro espaço profissional, relatou:

[...] Eu trabalhei na Educação Básica, mas [...] A minha experiência é [...] No que era o primeiro grau e o segundo grau, eu terminei o curso de licenciatura curta em ciências, prestei concurso no Estado para matemática, já estava dando aula, passei, fiz opção de lotar numa escola da periferia que foi lá no DNER, [...] Depois eu transferi lá para escola Ana Maria, e fui trabalhar no que era a delegacia regional de ensino que era como se fosse um escritório da secretaria de educação aqui, então, em determinado momento eu sai da sala de aula, acho que foi em 91. (DMAT, Entrevista - excerto Q3.2)

Ao analisar esse relato constatamos que o DMAT teve sua primeira experiência profissional atuando como professor em uma escola pública de Educação Básica, o que possivelmente trouxe saberes desse nível da educação que influenciou ou que ainda influencia os saberes da experiência na Educação Superior. E também, nesse mesmo trecho, o docente evidencia que, além da experiência em sala de aula, logo depois assumiu a gestão na secretaria da escola, obtendo, assim, também a experiência na gestão escolar.

Além disso, enfatizamos que o DMAT já atuava como professor na Educação Básica antes de ter se efetivado em concurso público na Educação Superior, o que, para Tardif (2014), são experiências que trazem saberes profissionais construídos do e no trabalho, na ação efetivada na prática. Ainda, se analisarmos os saberes docentes que favorecem as aprendizagens da docência universitária, essas experiências profissionais, ou seja, os saberes profissionais adquiridos, provavelmente significaram grandes influências para o profissional que ele se tornou, a partir do contexto vivido por ele naquele momento, na condição de professor da Educação Básica.

Em relação à concepção de docência e sobre o ser docente universitário, Bitencourt (2014) ressalta que esses fatores são significados e construídos antes mesmo de os docentes ingressarem na docência e terem seu primeiro contato com a sala de aula, pois eles possuem uma representação do que seja ser professor a partir dos saberes construídos ao longo da sua trajetória pessoal e das suas experiências que repercutem nos seus comportamentos pessoais e profissionais. Nesse sentido, o DMAT declarou que ser docente é ter responsabilidade com a formação de outros profissionais, conforme o excerto a seguir:

\footnotetext{
Eu acho ser professor é nobre demais, você tem na sua frente uma responsabilidade muito grande das pessoas que passam por você, porque querendo ou não você é um formador dos formadores, no nosso caso da licenciatura. Você é o formador do agrônomo quando você vai lá e assume uma disciplina de física, você é o formador do biólogo e se tivesse lá na área de saúde eu me aventuraria a ir lá trabalhar física, então, você transita formando pessoas em diversas áreas com uma responsabilidade muito grande, que são seres humanos. (DMAT, Entrevista - excerto Q2).
} 
Percebemos, na fala desse docente atuante no curso de licenciatura, que ele tem consciência de que a sua Pedagogia Universitária ultrapassa os limites de um único curso de graduação, refletindo-se na formação de outros profissionais, pois ele é, como menciona, um formador dos formadores, independente do curso em que atua, assim, mesmo que esse docente não defina sua ação como Pedagogia Universitária, percebe a sua influência (BITENCOURT, 2014).

Assim, destacamos que a Pedagogia Universitária se faz nas diferentes ações dos docentes em diferentes cursos e em interações entre estudantes-docentes-universidade, sendo essas possibilidades de (re)construção das aprendizagens e saberes da docência.

Ao adentrarmos nossas análises nas questões voltadas às fontes de aprendizagens do docente universitário compreendemos que o exercício da docência é uma profissão aprendida, em que não se nasce docente, mas aprende-se a sê-lo na prática cotidiana, nas experiências, em que os docentes, ao longo da sua trajetória, (re)constroem saberes para a sua atuação docente (SILVA; MONTEIRO, 2007).

Nesse sentido, destacamos o excerto do DMAT:

\begin{abstract}
Eu aprendo na sala de aula, mas nada que eu levo está esvaziado de leituras prévias, eu acho que tem uma gama de leituras atrás, muito pesada para que eu componha como é que eu vou trabalhar metodologicamente este conteúdo e este outro por outro caminho totalmente diferente. Então não é esvaziado de teoria essa prática, ela é uma práxis mesmo [...]. (DMAT, Entrevista - excerto Q8).
\end{abstract}

Na fala do DMAT evidenciamos que ele aprende a docência no cotidiano da prática docente, aprendendo na sala de aula, com leituras, em diálogos e interações com outras pessoas. Isso corrobora o que ressaltam Bolsan e Isaia (2010), ao dizerem que as construções das aprendizagens se fazem na prática da sala de aula e no exercício da atuação cotidiana do docente na universidade.

Na resposta do DMAT - docente licenciado - também constatamos que em momento algum ele menciona a sua formação inicial em licenciatura como contribuição para as aprendizagens da docência; apenas relata que aprende na sala de aula, na prática. Pressupomos que mesmo que não esteja explícita na sua fala essa contribuição, ele, de alguma maneira, expressa isso quando diz que nada é esvaziado de teoria e prática, pois, provavelmente, essa teoria foi estudada na sua graduação e a utiliza juntamente com outras atuais para ensinar seus estudantes. Nesse sentido, concordamos com Marcelo Garcia (1999), quando o autor ressalta que nenhum docente aprende a ensinar de forma mecânica, pois o professor insere em sua atuação uma gama de conhecimentos prévios quando realiza qualquer atividade. 
Em relação aos saberes mobilizados, percebemos, no decorrer da pesquisa, que o docente universitário tem a consciência de que mobiliza saberes para além dos disciplinares, mobilizando também os saberes pedagógicos, curriculares, profissionais, construídos ao longo da carreira docente. Porém, há certo estranhamento por parte do docente quando indagado sobre quais saberes mobiliza, não conseguindo elencá-los nos moldes da teoria estudada nesta pesquisa.

Dessa forma, entendemos que, ao longo da carreira docente, os docentes universitários vão adquirindo saberes experienciais que, para Bitencourt (2017), "são vivências que quando refletidas e significadas pelo sujeito tornam-se experiências”. Sendo assim, durante todo o percurso de vida pessoal e profissional desses docentes, os quais vão significando as experiências vividas na própria prática docente, sendo, portanto, (re)construídas as suas aprendizagens de/em docência.

\section{CONSIDERAÇÕES}

É premente enfatizar que todo o processo investigativo foi fruto de uma construção coletiva e colaborativa com os membros do Grupo de Estudos e Pesquisas sobre Formação e Docência (GFORDOC), isto porque, em nossos encontros, buscamos discutir a formação e a docência nos mais variados espaços, e para diferentes sujeitos e profissões, proporcionando, assim, a (re)construção dos nossos conhecimentos, saberes e aprendizagens.

A pesquisa aqui apresentada demonstra que cada docente possui, de forma singular, elementos que influenciam suas aprendizagens da docência, elementos compostos pelo entrelaçamento do seu percurso de formação pessoal e profissional, em que as aprendizagens se fazem e se refazem constantemente, conforme os saberes vão sendo significados por cada sujeito a partir das suas experiências.

Além disso, essa pesquisa nos proporcionou perceber que a Pedagogia Universitária está inserida como espaço de (re) construção das aprendizagens e saberes, mesmo que, muitas vezes, os próprios docentes não a reconheçam.

A partir da análise realizada constatamos que o docente universitário aprende a docência no cotidiano da sua prática docente, na sala de aula, a partir das interações com outros indivíduos, e, além disso, as suas experiências pré-profissionais e profissionais influenciam a sua aprendizagem e a significação dos seus saberes. 
Além disso, compreendemos que, mesmo o docente não explicitando os saberes mobilizados por ele em sua atuação, cada docente constrói seus saberes de acordo com a necessidade que encontra no exercício da docência, mobilizando saberes próprios e profissionais, pedagógicos, disciplinares e curriculares, todos fundamentados pelos saberes da experiência.

\section{REFERÊNCIAS}

BITENCOURT, L. P. Pedagogia Universitária potencializada no diálogo reflexivo sobre Educação Matemática: quando três gerações de educadores se encontram. 2014. 268 f. Tese (Doutorado) - Universidade Federal do Rio Grande do Sul, Faculdade de Educação, Programa de Pós-Graduação em Educação, Porto Alegre, RS, 2014. Disponível em: https://lume.ufrgs.br/bitstream/handle/10183/94629/000914883.pdf;jsessionid=D5B9B57B59 F8A6CF4A2B23582B9332D5? sequence=1. Acesso em: 20 fev. 2020.

; DARSIE, M. M. P. O formador de educadores matemáticos e sua aprendizagem para a docência. In: GONÇALVES, T. VALIM, O.; MACÊDO, F. C. da S.; SOUZA, F. L. Educação em Ciências e Matemáticas: debates contemporâneos sobre ensino e formação de professores. Porto Alegre, RS: Penso Editora. Grupo Artmed, 2015.

. Aprendizagem da docência do professor formador de educadores matemáticos. Curitiba: CRV, 2017.

BOGDAN, R. C.; BIKLEN, S. K. Investigação qualitativa em educação: uma introdução à teoria e aos métodos. Porto, PT: Porto Editora, 1994.

BOLSAN, D. P. V.; ISAIA, S. M. de A. Pedagogia Universitária e Aprendizagem Docente: relações e novos sentidos da professoralidade. Rev. Diálogo Educ., Curitiba, v. 10, n. 29, jan./abr., 2010. p. 13-26. Disponível em:

http://w3.ufsm.br/gtforma/estagio1/d495aa7de10b177529661cfe949317fe.pdf. Acesso em: 20 fev. 2020.

GALVÃO, F. N. dos S.; BITENCOURT, L. P. Pedagogia universitária e formação pedagógica do docente universitário: contributos para um ensino de qualidade e possíveis mudanças na universidade. Rev. Relva, v. 4, n. 1, Juara-MT, jan./jun., 2017. p. 9-23. Disponível em: https://periodicos.unemat.br/index.php/relva/article/view/2254. Acesso em: 20 fev. 2020.

A Pedagogia Universitária como espaço de (re)construção das Aprendizagens e Saberes da Docência nos cursos de Licenciaturas e Bacharelados da Unemat/CáceresMT. 2019. 187 f. Dissertação (Mestrado) - Universidade do Estado de Mato Grosso, Faculdade de Educação e Linguagem, Curso de Pós-Graduação Stricto Sensu (Mestrado Acadêmico) Educação, Cáceres, 2019. 
MARCELO GARCIA, C. Formação de professores: para uma mudança educativa. Porto, PT: Porto Editora, 1999.

MIZUKAMI, M. da G. N.; REALI, A. M. de M. R; REYES, C. R; MARTUCCI, E. M; LIMA, E. F de; TANCREDI, R. M. S. P; MELLO, R. R. de. Escola e aprendizagem da docência: processos de investigação e formação. São Carlos, SP: EdUFSCar, 2002.

PIMENTA, S. G. Formação de professores: identidade e saberes da docência. In: PIMENTA, S. G. (org.). Saberes Pedagógicos e Atividade Docente. 8. ed., São Paulo, SP: Cortez, 2012.

ANASTASIOU, L. das G. C. Docência no Ensino Superior. 5. ed., São Paulo, SP: Cortez, 2014.

SANTOS, E. G. dos; POWACZUK, A. C. H. Formação e desenvolvimento profissional docente: a aprendizagem da docência universitária. Políticas Educativas. Porto Alegre, RS; v. 5, n. 2, 2012. p. 38-53. Disponível em:

https://seer.ufrgs.br/Poled/article/view/35843/23273. Acesso em: 20 fev. 2020.

SILVA, A. M. de P. B. da; MONTEIRO, F. M. de A. Formação continuada e aprendizagem docente: relatos de professores que atuam na Educação de Jovens e Adultos (EJA). In: MONTEIRO, F. M. de A. (Org.). Trabalho docente na educação básica: contribuições formativas e investigativas em diferentes contextos. Cuiabá: EdUFMT, 2007. p. 59-72.

SOARES, S. R.; CUNHA, M. I. da. Formação do professor: a docência universitária em busca de legitimidade. Salvador: EDUFBA, 2010.

TARDIF, M. Saberes docentes e formação profissional. 17. ed., Petrópolis, RJ: Vozes, 2014.

ZABALZA, M. A. A universidade: cenário específico e especializado de formação. In.

ZABALZA, M. A. O ensino Universitário: seu cenário e seus protagonistas. Porto Alegre, RS: Artmed, 2004.

YIN, R. K. Estudo de caso: planejamento e métodos. 5. ed., Porto Alegre, RS: Bookman, 2015.

Submetido em: 20 de março de 2020.

Aprovado em: 07 de setembro de 2020 . 